\title{
Sistem Informasi Manajemen Proyek Perangkat Multimedia Berbasis Web Pada PT. Indovisual Presentatama
}

\author{
Ade Suryanto $^{1}$, Nandang Iriadi ${ }^{2}$, Ali Haidir ${ }^{3}$, Sulistiawan ${ }^{4}$ \\ ${ }^{1}$ Fakultas Teknik, Universitas Bina Sarana Informatika \\ e-mail: ${ }_{1}^{1}$ ade.ayo@bsi.ac.id \\ ${ }^{2}$ Fakultas Teknologi Informasi, Universitas Bina Sarana Informatika \\ e-mail: ${ }^{2}$ nandang.ndi@bsi.ac.id \\ ${ }^{3}$ Fakultas Teknologi Informasi, Universitas Bina Sarana Informatika \\ e-mail: ${ }^{3}$ ali.alh@bsi.ac.id \\ ${ }^{4}$ Sekolah Tinggi Manajemen Informatika dan Komputer Nusa mandiri \\ e-mail: ${ }^{4}$ whaone.x@gmail.com
}

\begin{tabular}{ccc}
\hline Diterima & Direvisi & Disetujui \\
$09-11-2019$ & $12-12-2019$ & $16-12-2019$ \\
\hline
\end{tabular}

\begin{abstract}
Abstrak - Saat ini PT. Indovisual Presentatama dalam hal menangani sistem manajemen untuk proyek-proyek yang sudah dilaksanakan saat ini masih bersifat manual dengan menggunakan metode yang dapat dikatakan belum terstruktur dengan baik, sehingga dalam beberapa hal sangat menyulitkan untuk dilaksanakannya tracking (pelacakan) dokumentasi proyek-proyek tersebut. Untuk sebuah proyek multimedia idealnya diperlukan sebuah manajemen dalam rangka mengatur agar proyek tersebut berjalan sesuai rencana, target dan sesuai harapan. Untuk hal itu sangat diperlukan sebuah sistem yang dapat mengakomodasi kebutuhan dokumentasi secara terstruktur, sehingga dengan sebuah sistem yang sudah terkomputerisasi maka diharapkan dapat memudahkan perencanaan dan implementasi sebuah proyek multimedia pada PT. Indovisual Presentatama. Oleh karena itu sebuah solusi sistem terkomputerisasi berbasis web atau online kami rasa dapat menjawab permasalahan tersebut, mengapa berbasis web, karena sistem akan mudah untuk diakses dimanapun dan kapanpun, basis data dapat dikelola secara cloud computing (komputasi awan) hal tersebut untuk meminimalisir kehilangan data-data serta dapat dengan mudah untuk dilakukan backup data.
\end{abstract}

Kata Kunci: Manajemen, Proyek, Website

\begin{abstract}
Currently PT. Indovisual Presentatama in terms of handling management systems for projects that have been carried out is still manually, with methods unstructured not well can be done easily, in some cases making it difficult to track. For an ideal multimedia project, a management is needed in order to make the project run according to plan, target and as expected, for that it is necessary for a system that can be used together, with a computerized system in order to plan and implement a project multimedia at PT. Indovisual Presentatama. Therefore, our web / online computerized system can provide different, web-based information, because web / online-based systems can be accessed anywhere and anytime, the database can be managed in cloud computing (cloud computing) that can minimize data loss can also be easily used to backup data.
\end{abstract}

Key word : Management, Project, Website

\section{PENDAHULUAN}

PT. Indovisual Presentatama bergerak pada bidang proyek perangkat multimedia (audio visual sistem), memiliki beberapa jenis produk atau barang audio visual dengan metode penjualan melalui sistem proyek, sehingga membutuhkan manajemen khusus untuk mendukung keberhasilan proyek tersebut. Untuk saat ini manajemen yang diberlakukan masih bersifat sangat sederhana dalam arti masih menggunakan pencatatan secara manual pada tiap-tiap proyek yang dikerjakan, sehingga hal tersebut menyebabkan kurangnya singkronisasi antar team terkait pada proyek- proyek tersebut yang dikerjakan oleh PT. Indovisual Presentatama, pada kasus yang pernah terjadi adalah adanya kesulitan delegasi kepada personil atau team dikarenakan dokumentasi yang tidak terstruktur sehingga saat pengalihan tugas diperlukan penjelasan lisan yang kadang tidak efektif serta informasi cenderung kurang detail karena minimnya data yang informatif.

Menurut (Purwanto \& Sari, 2015) dalam jurnalnya menyatakan bahwa Telah teridentifikasikan beberapa masalah pada manajemen proyek PT. Agate International. Kendala pada perusahaan yang berhubungan dengan manajemen proyek meliputi optimalisasi kerja tim, belum 
terdefinisinya metrik standar, dan manajemen perubahan, dimana perusahaan dan klien sering kesulitan untuk mengkomunikasikan kebutuhan mereka untuk mendefinisikan tujuan sebuah proyek. Oleh karena itu penelitian bertujuan untuk melakukan analisis kesenjangan antara praktik perusahaan dengan best practice CMMI agar evaluasi dan saran untuk perbaikan dapat dibentuk. Model CMMI digunakan karena dapat mendukung praktik perusahaan yang bersifat Agile. Jenis penelitian adalah kualitatif deskriptif. Informan dari perusahaan adalah kepala HR sekaligus Cofounder perusahaan, produser senior, dan produser perusahaan. Analisis kesenjangan disajikan lewat narasi yang menjelaskan perbandingan antara praktik area proses perusahaan dengan CMMI. Bukti pendukung dokumentasi artifak juga dikumpulkan dan disajikan untuk mendukung keabsahan data. Hasil penelitian menyimpulkan bahwa perusahaan telah mecapai kapabilitas tingkat satu untuk area proses Requirement Management, Project Planning, dan Project Monitoring \& Control.

Saran yang dapat diberikan adalah pendefinisian beberapa praktik perusahaan yang sifatnya masih ad-hoc agar sebuah proses dapat lebih mudah dimengerti, dan dijadikan panduan untuk melakukan estimasi proyek kerja yang lebih akurat. Pendefinisian proses yang lebih mendetail juga diperlukan agar tingkat kapabilitas area proses perusahaan dapat ditingkatkan.

Menurut (Somya, 2018) pad jurnalnya, PT. Pura Barutama merupakan perusahaan yang bergerak dibeberapa bidang usaha, diantaranya yaitu percetakan, pengepakan, pembuatan kertas, konversi, rekayasa, anti pemalsuan, dan teknologi kartu elektronik dan label. Unit Pura Bangunan merupakan salah satu unit PuraGroup yang bertugas untuk membuat bangunan baru dan renovasi bangunan. Namun, hingga saat ini permintaan untuk membangun bangunan baru atau renovasi bangunan dari berbagai unit masih diproses dengan melakukan request pembuatan memo ke Pura Bangunan kemudian mengambil berkas memo di Pura Bangunan untuk disetujui oleh bagian umum, cost control, dan pimpinan unit tersebut. Selanjutnya dikumpulkan kembali berkas memo tersebut ke PuraBangunan. Kemudian dalam monitoring pembuatan pra Rencana Anggaran Biaya (RAB), rancangan gambar bangunan, RAB, Surat Keputusan Kerja (SPK), ketersediaan material, hingga progress pelaksanaan pembangunan oleh admin dan pimpinan unit seringkali tidak akurat dan real time. Hal tersebut tidak efisien dan efektif karena proses request pembuatan memo membutuhkan waktu sekitar 1-2 hari, memo yang telah dikumpulkan ke Pura Bangunan terkadang hilang, dan monitoring proyek tidak optimal. Unit Pura Bangunan melakukan inovasi dengan melakukan request ke unit khusus Management Information System (MIS) yang bertugas dalam penanganan masalah teknologi informasi Pura Group untuk membuat aplikasi yang dapat memudahkan berbagai unit dalam melakukan request dan monitoring.

Menurut (Arianie \& Puspitasari, 2017) dalam jurnalnya menyatakan bahwa Manajemen proyek merupakan strategi yang perlu dilakukan dalam mencapai efisiensi dan efektifitas suatu perusahaan. Perkembangan pada era teknologi masa ini sejalan dengan berkembangnya perusahaan yang bergerak di bidang jasa teknologi, seperti Qiscus Pte Ltd. Perencanaan proyek tersebut dapat disusun menggunakan Work Breakdown Structure (WBS), Cirital Path Method (CPM) dan Program Evaluation

and Review Technique (PERT). Manajemen proyek dapat pula digunakan untuk memperkirakan adanya percepatan proyek (crasing) pada Qiscus Pte Ltd. Dengan penyusunan suatu manajemen proyek yang baik, maka dapat dilakukan estimasi waktu dan biaya yang diperlukan dalam menjalankan proyek, sehingga dapat meminimasi kerugian biaya akibat kemungkinan keterlambaran proyek. Perencanaan manajemen proyek yang dilakukan untuk menjalankan proyek Hayyan, Qiscus Pte Ltd, menghasilkan estimasi percepatan pengerjaan proyek selama 6 hari, dengan penambahan biaya sebesar 2,8 juta.

\section{METODOLOGI PENELITIAN}

Teknik dalam pengumpulan data yang dilakukan dalam penelitian ini menggunakan :

\section{A. Observasi}

Penulis melakukan observasi atau pengamatan secara langsung dan ikut terlibat dalam proyek yang sedang berlangsung atau yang sedang dikerjakan oleh PT. Indovisual Presentatama

\section{B. Wawancara}

Penulis melakukan sesi wawancara dengan penanggung jawab proyek dan diberikan informasi berdasarkan apa yang menjadi pertanyaan penulis, selain daripada itu penulis juga melakukan wawancara dengan manajer Product Technical Support selaku pimpinan teknis sistem yang sedang dikerjakan.

\section{Studi Pustaka}

Penulis melakukan studi pustaka dengan mengumpulkan informasi dari data-data proyek serta mempelajari dokumentasi yang ada. Serta mencari sumber-sumber pendukung lainnya yang dibutuhkan seperti buku, jurnal dan literatur di internet.

Model dalam Pengembangan Sistem pada penelitian ini dilakukan dengan cara :

A. Analisa Kebutuhan Software

Pada tahap ini penulis mempelajari proses bisnis yang ada pada PT Indovisual Presentatama untuk 
menganalisa dan memahami perangkat lunak yang dibutuhkan serta batasan perangkat lunak.

\section{B. Desain}

Pada tahap ini penulis melakukan desain sistem sesuai dengan analisis kebutuhan sistem yang diminta, dalam tahap ini penulis juga menggambarkan use case diagram dan activity diagram sesuai dengan proses bisnis yang sudah berjalan untuk membuat rancangan database, software architecture menggunakan UML (Unified Modeling Language), selanjutnya untuk mendesain database menggunakan ERD (Entity Relationship Diagram), sedangkan untuk mendesain user interface menggunakan CSS (Cascading Style Sheet).

\section{Code Generation}

Untuk menerapkan sistem manajemen proyek berbasis online pada PT Indovisual, penulis menggunakan bahasa pemrograman PHP, HTML, CSS dan menggunakan database MySQL. Adapun teknik pemrograman yang digunakan adalah teknik pemrograman terstruktur.

\section{Testing}

Pada tahap ini penulis menggunakan black box testing untuk mengetahui dan menguji bagaimana program yang telah dibuat dan mengetahui kekurangan program tersebut.

\section{E. Support}

Perangkat lunak yang sudah berhasil dibuat kemudian dijalankan serta dilakukan pemeliharaan, memperbaiki kesalahan yang mungkin tidak ditemukan pada tahap atau langkah sebelumnya, pada tahap ini juga termasuk untuk melakukan pembaruan atau update data, agar selalu up to date atau terkini.

\section{HASIL DAN PEMBAHASAN}

Sistem informasi manajemen proyek pada PT. Indovisual Presentatama merupakan media untuk mempermudah mendapatkan informasi terkait sebuah proyek yang sedang dikerjakan. Berikut ini adalah spesifikasi kebutuhan dari sistem :

Halaman Sales :

A1.Sales melakukan login terlebih dahulu

A2.Sales melihat dashboard

A3.Sales dapat melakukan upload purchase order

A4.Sales menerima tagihan purchase order dari admin

A5.Sales dapat berkomunikasi dengan marketing

Halaman Marketing :

B1. Marketing melakukan login terlebih dahulu

B2. Marketing melihat dashboard

B3. Marketing menerima purchase order dari sales

B4. Marketing menerima file barang dari gudang

B5. Marketing melihat file tagihan purchase order dari admin

B6. Marketing meng-upload file untuk Admin
B7. Marketing meng-upload data proyek untuk PTS

B8. Marketing dapat berkomunikasi dengan Sales, Gudang, Admin dan PTS

Halaman Gudang :

C1.Gudang melakukan login terlebih dahulu

C2.Gudang melihat dashboard

C3.Gudang melakukan upload data barang untuk marketing

C4.Gudang dapat berkomunikasi dengan marketing

Halaman Admin :

D1Admin melakukan login terlebih dahulu

D2.Admin melihat dashboard

D3. Admin dapat melihat purchase order yang masuk dari marketing

D4. Admin mengirim tagihan purchase order kepada sales

D5.Admin dapat berkomunikasi dengan marketing

Halaman PTS :

E1.PTS melakukan login terlebih dahulu

E2.PTS melihat dashboard

E3.PTS melihat informasi proyek dari marketing

E4. PTS melakukan upload laporan penggerjaan proyek

E5.PTS dapat berkomunikasi dengan marketing

Use case diagram bertujuan untuk menggambarkan fungsionalitas yang diharapkan dari sebuah sistem, sebuah use case mempresentasikan sebuah interaksi antara actor dengan sistem, use case merupakan sebuah pekerjaan tertentu.

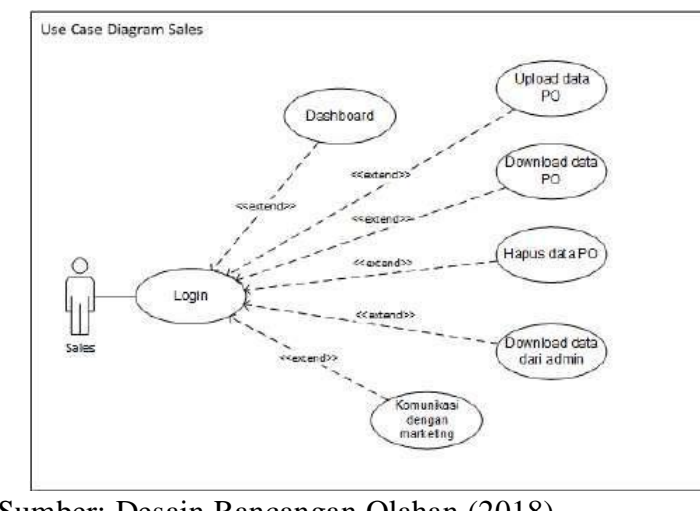

Sumber: Desain Rancangan Olahan (2018)

Gambar 1.

Use Case Diagram Halaman Sales 
Tabel 1

Deskripsi Use Case Halaman Login Sales

\begin{tabular}{|c|c|}
\hline Use Case Name & Login \\
\hline Requirement & A1 \\
\hline Goal & $\begin{array}{ll}\text { User masuk } & \text { kedalam } \\
\text { halaman utama Sales } & \end{array}$ \\
\hline Pre-Conditions & $\begin{array}{ll}\text { User masuk } & \text { kedalam } \\
\text { Halamanindex yaitu } & \\
\text { halaman login Sales } & \\
\end{array}$ \\
\hline Post-Conditions & $\begin{array}{l}\text { User memasukan } \\
\text { username dan password }\end{array}$ \\
\hline $\begin{array}{ll}\text { Failed } & \text { End } \\
\text { Conditions } & \end{array}$ & $\begin{array}{l}\text { User gagal } \\
\text { kehalaman utama }\end{array}$ \\
\hline Primary Actor & Sales \\
\hline $\begin{array}{l}\text { Main Flow/Basic } \\
\text { Path }\end{array}$ & $\begin{array}{l}\text { User dapat } \\
\text { halaman sales }\end{array}$ \\
\hline Invariant & $\begin{array}{l}\text { User merefresh halaman } \\
\text { User membatalkan login }\end{array}$ \\
\hline
\end{tabular}

Sumber: Desain Rancangan Olahan (2018)

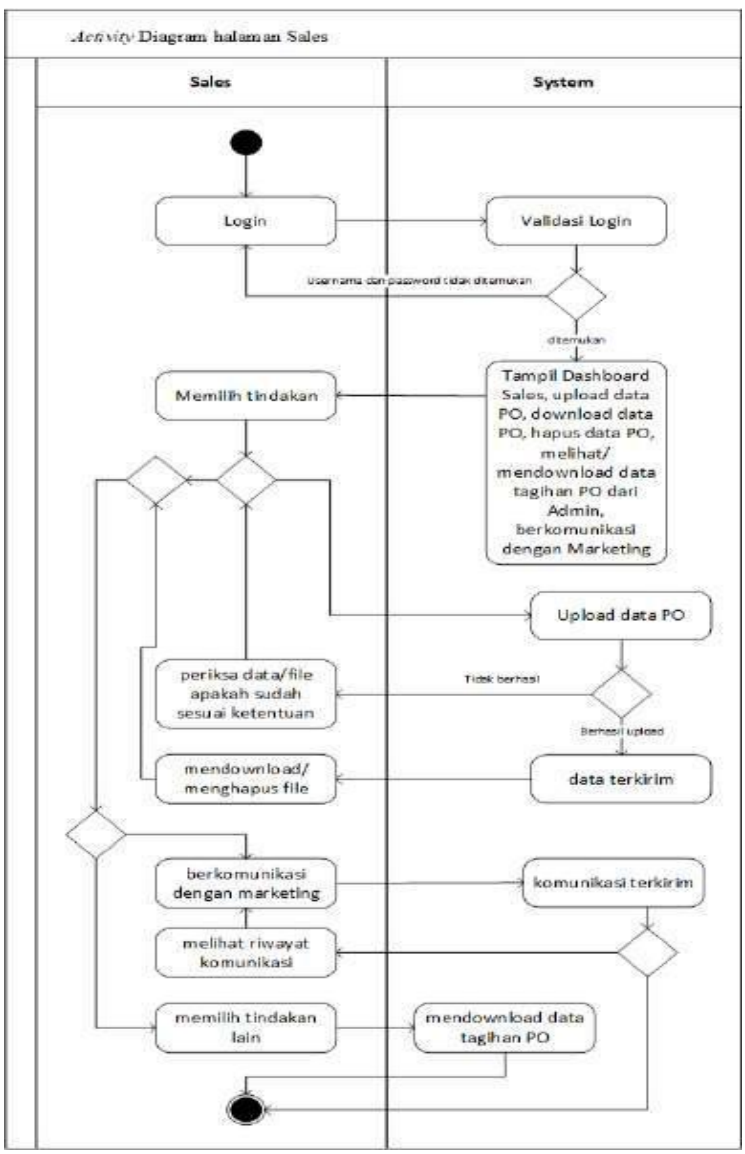

Sumber: Desain Rancangan Olahan (2018)

Gambar 2

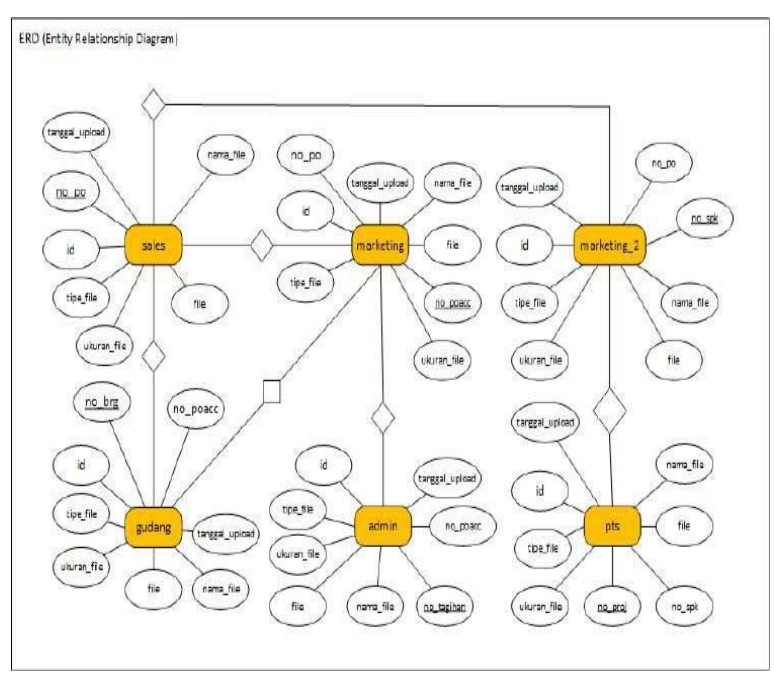

Sumber: Desain Rancangan Olahan (2018)

Gambar 3

$E R D$

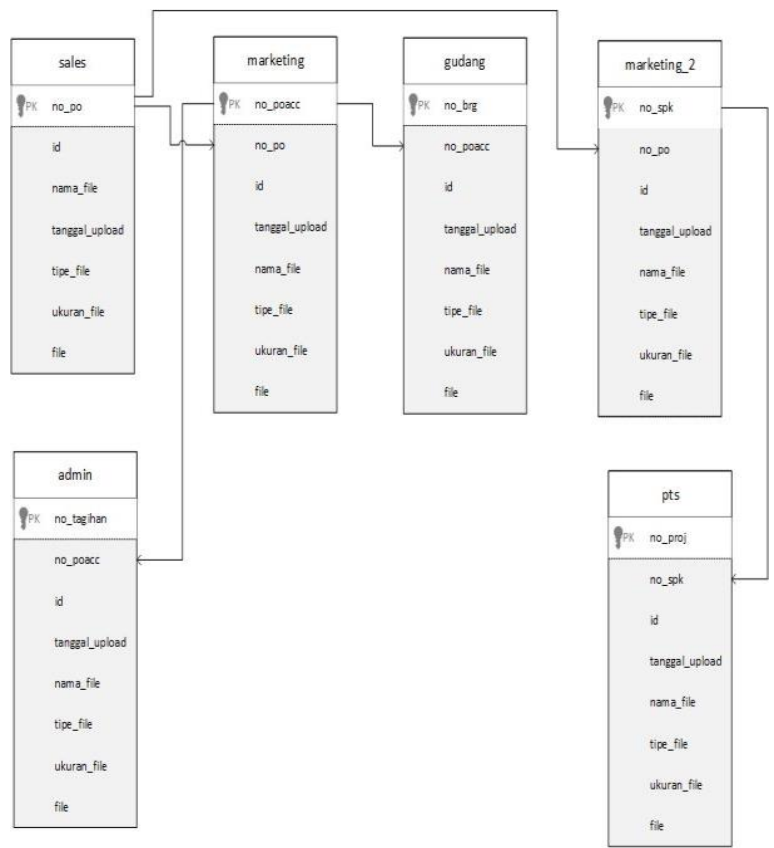

Sumber: Desain Rancangan Olahan (2018)

Gambar 4

LRS

Activity Diagram halaman Sales 


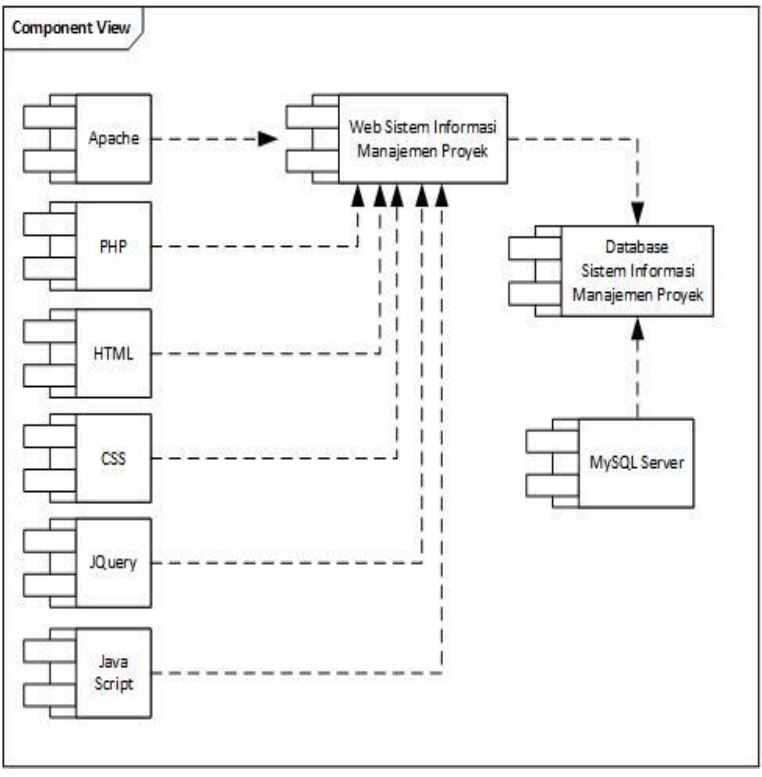

Sumber: Desain Rancangan Olahan (2018)

Gambar 5

Component Diagram Sistem Informasi Manajemen Proyek

Pada Component Diagram tersebut diatas merupakan komponen-komponen perangkat lunak yang terdapat pada sistem informasi manajemen proyek yang tergabung membentuk kesatuan sistem.

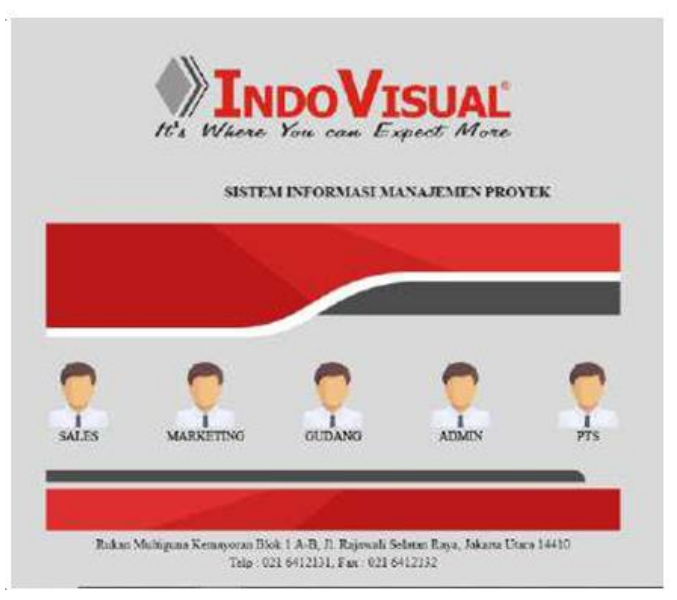

Sumber: Aplikasi Usulan (2018)

Gambar 6

Halaman utama

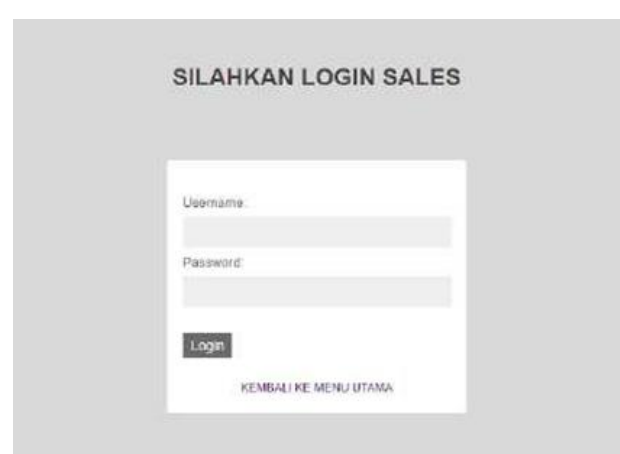

Sumber: Aplikasi Usulan (2018)

Gambar 7

Halaman login sales

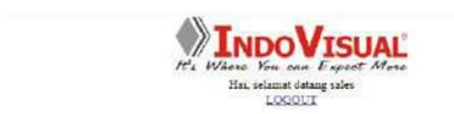

SISIEM INFORUAST MAANAJMEX PROYEK (HALAMLN SALES)

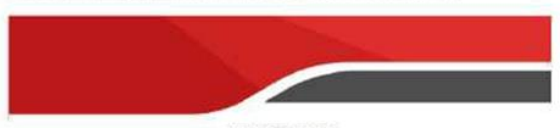

UPLOADDATA PO

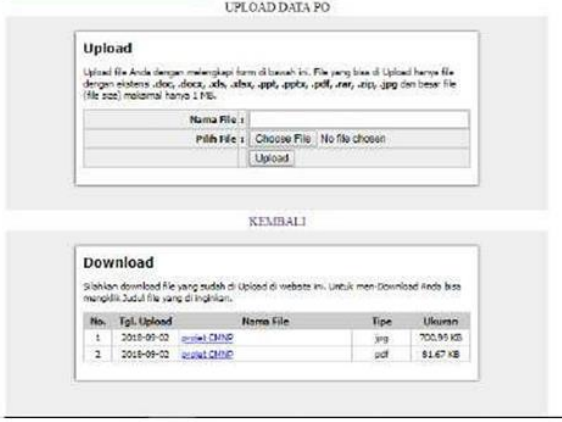

Sumber: Aplikasi Usulan (2018)

Gambar 8

Halaman dashboard sales

\section{Spesifikasi Hardware Dan Software}

Pada tahap ini penulis akan menjelaskan kebutuhan hardware dan software yang dibutuhkan untuk menjalankan sistem usulan. Beriku tabel kebutuhan hardware dan software:

Tabel 2

Tabel Spesifikasi Kebutuhan Hardware Dan Software

\begin{tabular}{|l|l|}
\hline \multicolumn{1}{|c|}{ Kebutuhan } & \multicolumn{1}{|c|}{ Keterangan } \\
\hline Sistem Operasi & Windows 7 \\
\hline Processor & Intel core 2 duo, 2.4 Ghz \\
\hline RAM & $2 \mathrm{~GB}$ \\
\hline Monitor & LCD \\
\hline
\end{tabular}




\begin{tabular}{|l|l|}
\hline Keyboard & 108 key \\
\hline Printer & Laser Jet, ink Jet \\
\hline Mouse & Standart \\
\hline Browser & $\begin{array}{l}\text { Mozilla firefox } \\
\text { Google Chrome }\end{array}$ \\
\hline Software & $\begin{array}{l}\text { Adobe } \\
\text { Dreamweaver } \\
\text { Adobe photoshop } \\
\text { CS6 } \\
\text { XAMPP }\end{array}$ \\
\hline
\end{tabular}

\section{KESIMPULAN}

Setelah melakukan penelitian dan mempelajari permasalahan yang terjadi pada kegiatan proyekproyek divisi IVS PT. Indovisual Presentatama, maka penulis memiliki rangkuman kesimpulan yaitu sebagai berikut :

a. Pada sistem informasi manajemen proyek ini penulis berusaha memberikan sebuah solusi untuk pendokumentasian proyek yang dikerjakan oleh divisi IVS pada PT. Indovisual Presentatama dimana tiap proyek yang dikerjakan memiliki tingkat kesulitan berbedabeda dengan durasi pengerjaan juga berbedabeda, dengan demikian diperlukan pencatatan riwayat pengerjaan proyek tersebut untuk studi kasus proyek-proyek lainya.

b. Dengan adanya sistem informasi manajemen proyek ini diharapkan adanya kemudahan melakukan penyatuan informasi dari beberapa sumber terkait proyek yang dikerjakan. c. Diharapkan adanya kemudahan dalam penyimpanan data-data proyek sehingga dapat dengan mudah untuk diakses dikemudian hari.

d. Dengan sistem informasi manajemen proyek yang bersifat online maka data-data yang tersimpan

dapat dengan mudah diakses dari manapun dan kapanpun.

\section{REFERENSI}

Arianie, G. P., \& Puspitasari, N. B. (2017). PERENCANAAN MANAJEMEN PROYEK DALAM MENINGKATKAN EFISIENSI DAN EFEKTIFITAS SUMBER DAYA
PERUSAHAAN (Studi Kasus: Qiscus Pte Ltd). J@ti Undip: Jurnal Teknik Industri, 12(3),

189. https://doi.org/10.14710/jati.12.3.189-196

Enterprise, J. (2014). BUKU PINTAR HTML5+CSS3+DREAMWEAVER.

Hellyana, C. M. (2015).Penggunaan Sistem Aplikasi Redmine Dan Subversion Dalam Manajemen Proyek. Evolusi, (1), 11-20.

Hutahaean, J. (2015). KONSEP SISTEM INFORMASI.

Nurhayati dkk. (2016).

PERENCANAAN MANAJEMEN PROYEK JARINGAN KOMPUTER PADA PT LOVALATTES INDONESIA Teknik Informatika, Fakultas Sains dan Teknologi UIN Syarif Hidayatullah Jakarta Along with the times and information technology, and human needs to a problem that high job dema, 9(1), 78-90.

Paramita, D. (2015). Rancang Bangun Sistem Informasi Kolaboratif Berbasis Web Untuk Manajemen Proyek Teknologi Informasi, 195-202.

Purwanto, R. A., \& Sari, P. K. (2015). Analisa Tingkat Kapabilitas Manajemen Proyek Pt . Agate International Dengan Menggunakan Model Cmmi Capability Level Analysis on the Project Management of Pt . Agate International With Cmmi Model. 2(3), 23622369.

Puspitasari, D. (2016). Sistem Informasi Perpustakaan Sekolah Berbasis Web. Jurnal Pilar Nusa Mandiri, 12(2), 227-240.

Rosa dan Shalahuddin. (2016).REKAYASA PERANGKAT LUNAK.

Setiawan, H., \& Khsiruzzaman, M. Q. (2017). Perancancangan Sistem Informasi Manajemen Proyek Sistem Informasi Kontraktor. Jurnal Teknologi Informasi DINAMIK Volume XIV, $\mathrm{V}(2), 28-39$.

https://doi.org/10.25126/jtiik.201851539

Somya, R. (2018). Aplikasi Manajemen Proyek Berbasis Framework CodeIgniter dan Bootstrap di PT. Pura Barutama. Jurnal Informatika: Jurnal Pengembangan IT, 3(2), 143-150. https://doi.org/10.30591/jpit.v3i2.726

Syahputra, D. (2017). Pembangunan Perumahan Pada PT. Perkasa Properti Menggunakan Metode Critical Path Method ( Cpm ) Dan Pert, XII, 10 14. 